\title{
Customer Participation in New Product Development and New Product Performance: The Moderating Role of Expertise
}

\author{
Todd Morgan and Michael Obal
}

\begin{abstract}
New product developers have increasingly utilized input from customers to co-create innovative new products. However, while much of the extant literature focuses on the positive side of customer participation on the new product development (NPD) process, significantly less work has focused on the negative side of co-creation. This study contends that a customer participation paradox exists: while customer participation in NPD may potentially help product performance, it could also lead to the development of products that are overly radical and are too difficult for potential customers to understand. To resolve this paradox, we argue that firms with higher levels of expertise will be able to rein in the negative aspects of extreme product newness to create products that will be in high demand by the marketplace. A survey of 305 firms involved in NPD activities was used to test our conceptual model. The results show that customer participation in the NPD process leads to overly new products that do not perform well on the market. Further, a multi-group analysis reveals that customer participation in NPD only has a positively influence on product performance for firms with high levels of expertise. The findings from this study demonstrate that while customer participation in NPD is beneficial for firms with high expertise, it may actually have a detrimental impact on product performance for those firms with low ACAP.
\end{abstract}

\footnotetext{
T. Morgan ( $\square)$

Kent State University, Kent, OH, USA

e-mail: tmorga14@kent.edu

M. Obal

University of Massachusetts Lowell, Lowell, MA, USA

e-mail: michael_obal@uml.edu
} 